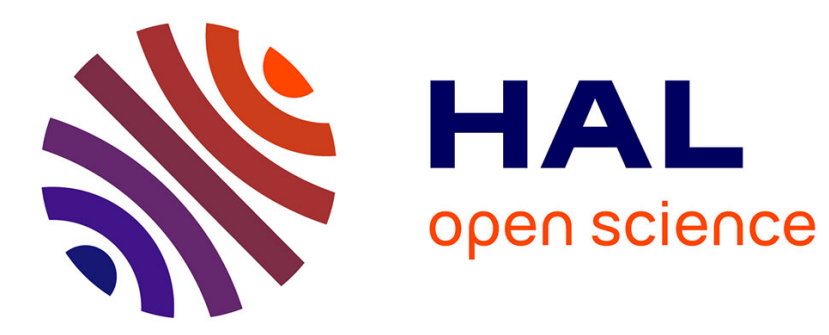

\title{
Analyze of the contact behavior between two layers of dry glass plain weave fabric
}

Samir Allaoui, Gilles Hivet, Pierre Ouagne

\section{To cite this version:}

Samir Allaoui, Gilles Hivet, Pierre Ouagne. Analyze of the contact behavior between two layers of dry glass plain weave fabric. Key Engineering Materials, 2012, 504-506, pp.313-318. 10.4028/www.scientific.net/KEM.504-506.313 . hal-00772352

\section{HAL Id: hal-00772352 \\ https://hal.science/hal-00772352}

Submitted on 10 Jan 2013

HAL is a multi-disciplinary open access archive for the deposit and dissemination of scientific research documents, whether they are published or not. The documents may come from teaching and research institutions in France or abroad, or from public or private research centers.
L'archive ouverte pluridisciplinaire HAL, est destinée au dépôt et à la diffusion de documents scientifiques de niveau recherche, publiés ou non, émanant des établissements d'enseignement et de recherche français ou étrangers, des laboratoires publics ou privés. 


\title{
Analyze of the contact behaviour between two layers of dry glass plain weave fabric
}

\author{
S. Allaoui, G. Hivet, P. Ouagne \\ Laboratoire PRISME/MMH, UPRES EA 4229, Université d'Orléans, Polytech'Orléans, 8 rue \\ Léonard de Vinci 45072 Orléans Cedex 2, France. \\ samir.allaoui@univ-orleans.fr, gilles.hivet@univ-orleans.fr, pierre.ouagne@univ-orleans.fr
}

Keywords: Contact, Dry Fabric, Friction, RTM, Woven reinforcement.

\begin{abstract}
.
The market demand for thicker complex shaped structural composite parts is increasing. Processes of the Liquid Composite Moulding (LCM) family, such as Resin Transfer Moulding (RTM) are considered to manufacture such parts. The first stage of the RTM process concerns the preforming of the part. During the preforming of multi-layered reinforcements, friction between the plies occurs and needs to be characterize and then to be taken into account for the forming simulation. An experimental device designed to analyze the ply/ply, ply/tool and yarn/yarn frictions has been built. Tests carried out on a glass plain weave highlight specific contact behaviour for dry reinforcement fabric in comparison to non-technical textiles. This behaviour exhibits a substantial variation of the contact tangential loads which is directly related to shocks between the yarns. It demonstrated that period and amplitude of the friction response is directly related to the relative positioning of the samples but also to fabric meso-strucrure. In addition, the sample relative orientation has a significant influence on the friction response. The meso-architecture is responsible for the high variations of the friction coefficient as a function of the ply orientations for different fabrics. In addition, the friction response appears to be very sensitive to tests parameters like the relative positioning, orientation of the samples and the cycling. A honing effect classically observed in dry fabric testing has also been pointed out through cyclic experiments. It can be attributed to both fibre material abrasion and fibre reorganisation inside the yarn.
\end{abstract}

\section{Introduction}

The transport sector is one of the fastest growing consumer of energy and producer of greenhouse gases in the world. Consequently, transportation energy consumption, and thus the global warming, can be reduced by reducing the mass of the transportation means. The composite materials are able to propose credible answers to the optimization of the thick structural parts with significant size through their good ratio strength/weight and especially their anisotropy which can be adapted to the mechanical solicitation of the structure. To manufacture the composites pieces, the RTM is the more interesting process because it offers the best compromise in terms of repeatability, production rates and low final cost. The first step of the process consists in draping a dry preform before injection of the liquid resin. The preforming stage is a delicate phase. Indeed, the mechanisms taking place during this stage are complex, very different than the ones occurring during the stamping of metallic sheets and are far from being fully understood [1].

Many methods have been proposed recently to achieve representative sheet forming simulations of dry fabric, with different approaches [2-3]. Several key entry parameters for the simulation models need to be determined experimentally. The mechanical properties of a single layer of different types of woven fabric reinforcement plies have been widely studied [4-6]. In addition to the reinforcement properties, the fabric/tool contacts and, for those dealing with multiply forming, the fabric/fabric contact has to be studied and modelled. The tool/fabric contact and to a lower extend the yarn/yarn contact have been investigated by different authors for carbon fibrereinforced thermoplastics or dry fabrics [7-9]. For thick composite parts fabric/fabric contact intervening between layers and must be studied and modelled in order to better optimize the RTM process and to avoid defects appearance. The numerical studies carried out to simulate multi-layer 
forming of dry fabrics use an approximate ply/ply friction coefficient not dependant on the yarn angle [3] whereas preliminary forming tests conducted on a stack of reinforcement confirmed the significant influence of the relative positioning between dry plies [10] and therefore contact between layers. For this aim, a specific device has been built in our lab [11]. The first results show the effect of the woven meso-structure on the fabric/fabric behaviour [12].

The goal of this paper is to propose an analysis of a of the contact behaviour between two layers of glass plain weave fabric and the influence of some parameters such as the relative positioning of the samples, the relative angle between the two layers and the cycling.

\section{Description of the friction device}

When considering experimental investigations of dry-fabric friction, various mesoscopic heterogeneities with very different unit cell sizes and anisotropy should be considered. This requirement suggests that specific experimental equipment should be considered to take into account these details. A specific experimental device dedicated to this task has consequently been designed in the lab [11]. The classical principle consisting of two plane surfaces sliding relative to each other is considered to be the most promising for this study (Fig. 1.a). This experimental principle is furthermore directly related to the inter-ply sliding during forming. The bottom sample (60 $\mathrm{cm}$ long and $9 \mathrm{~cm}$ wide) is fixed on a steel plate. It is rigidly and accurately guided by a linear system to translate horizontally in a fixed direction. A motor and an electronic speed controller are used to impose the required displacement. The top sample $(10 \mathrm{~cm}$ long and $8 \mathrm{~cm}$ wide $)$ is fixed on a steel plate which is linked to the load sensor. The lateral positioning of the upper sample is ensured by a linear joint. The load sensor is calibrated and used in the $0-20 \mathrm{~N}$ range to get $0.01 \mathrm{~N}$ accuracy. A data acquisition system is used to record measurements.

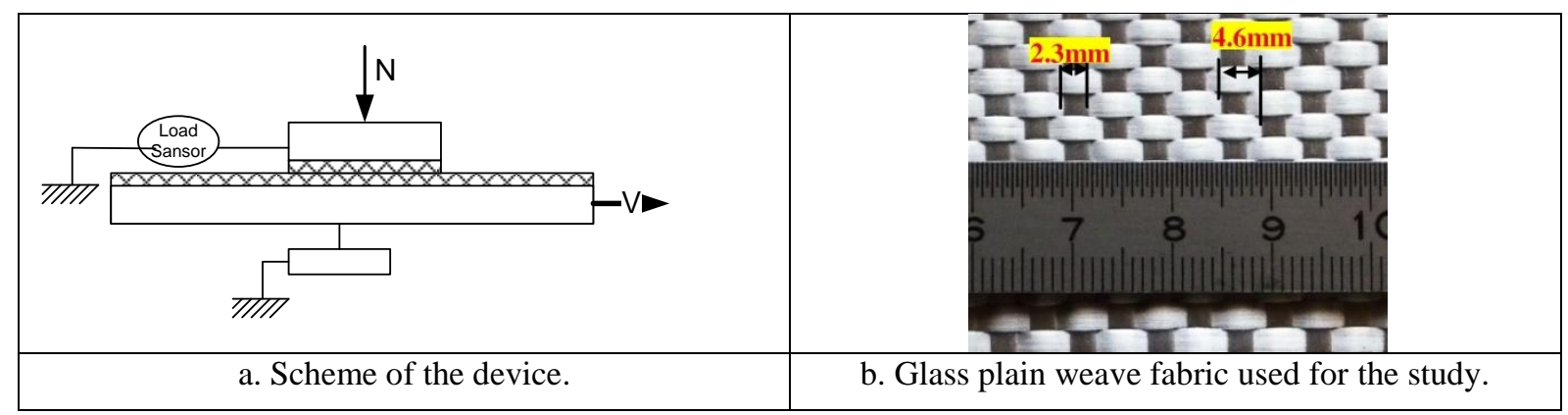

Figure 1 : Device principles and fabric used for the study.

\section{Materials of the study}

The fabric used in this study is a commercial glass plain weave fabric (Fig. 1.b). It is a 0.6 $\mathrm{mm}$ thickness Tissa+ glass plain weave with an areal weight of about $740 \mathrm{~g} / \mathrm{m}^{2}$. The yarns have widths of a $2.1 \mathrm{~mm}$ and an average spacing between yarns of $2.3 \mathrm{~mm}$.

\section{Phenomena governing the fabric/fabric contact behaviour}

The friction tests carried out on the fabric/fabric were conducted at classical environmental conditions $\left(\mathrm{T} \sim 23^{\circ} \mathrm{C}\right)$. The displacement speed for the bottom sample used in this study is defined after preliminary results of the preforming and contact friction tests realized in our lab. The value chosen is a $5 \mathrm{~mm} / \mathrm{s}$ which is deducted from the relative displacement between plies occurs during multi-ply forming of complex double curved dry preform. To analyze more accurately the signal variations, tests at a high sampling frequency have been performed. A $3 \mathrm{~ms}(333 \mathrm{~Hz})$ acquisition period to distinguish the frequencies of the different physical phenomena taking place during the measurement is considered. 
The friction coefficient $\mu$ is assumed to be calculated using the coulomb's theory:

$$
\mu=\frac{T}{N}=\frac{T}{M \cdot g} .
$$

Where $\mathrm{T}$ is the tangential load measured by the sensor, $\mathrm{N}$ is the normal load and $\mathrm{M}$ is the total mass of the upper specimen. We note that the pressure distribution on the contact surface between the two samples was established and controlled during the tests. For all the tests presented in this study, the normal load used is $\mathrm{N}=10 \mathrm{~N}$ which corresponds to a normal pressure of $1.25 \mathrm{KPa}$.

Figure 3 shows an example of the contact behaviour of the glass plain weave fabric where there are all phenomena observed during all the friction tests. As it was expected, specific behaviour was observed for dry fabric/fabric in comparison to non technical textiles (garments...), yarn/yarn or fabric/metal (Fig. 2.a). Particularly, variations of the contact tangential loads appeared to be very substantial while all the test parameters remained constant. Consequently, using an average friction coefficient will lead to a high amount of uncertainties in the mechanical analysis of these materials (Fig. 2.b).

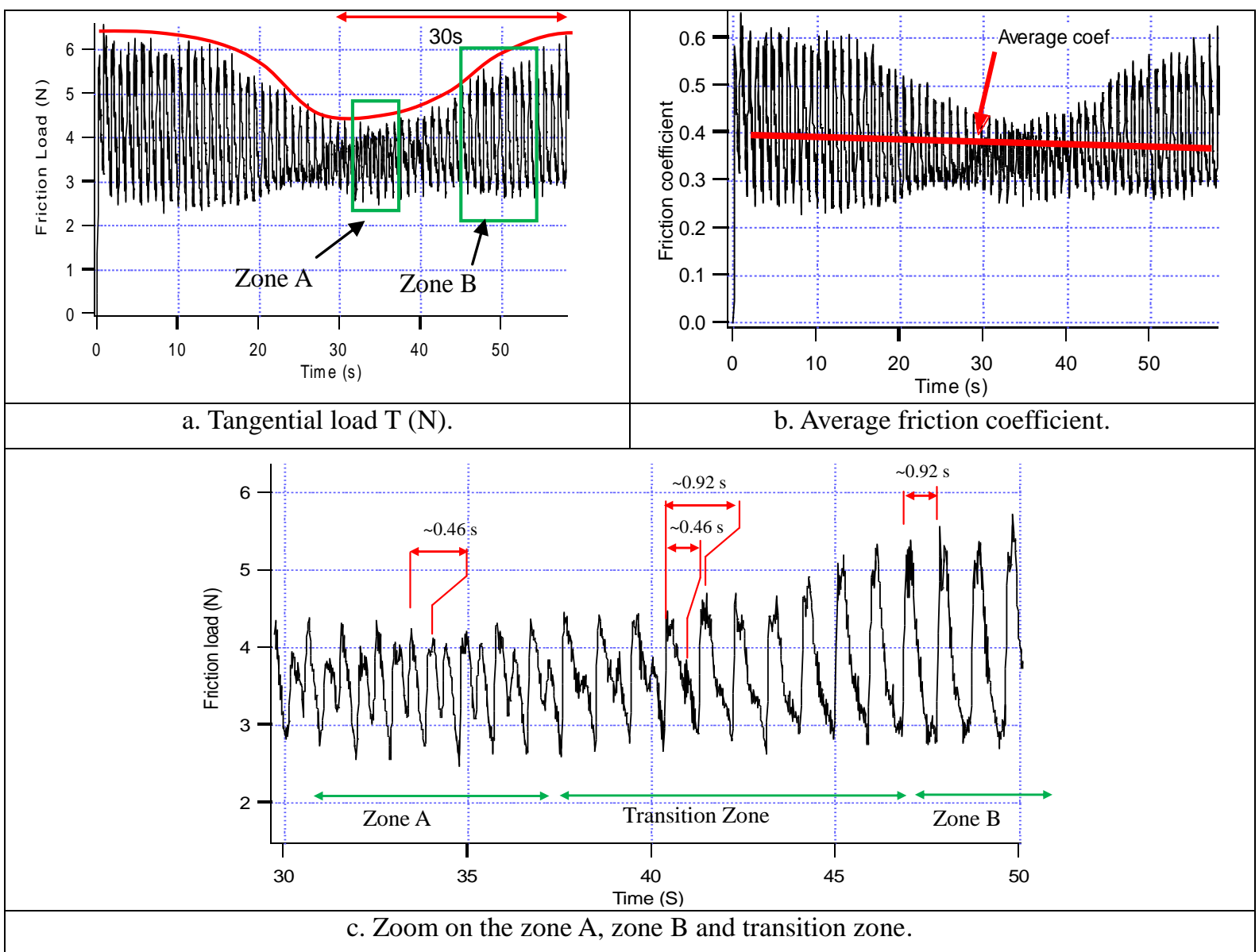

Figure 2 : Experimental results for the Glass plain weave, v=5mm/s, N=10N, 333 Hz sampling.

A more accurate analysis of the response enables us to distinguish two characteristic pseudo periods and three different zones (zone A, zone B and transition zone). The zone B is associated to the first period which represents the interval between two maximum load values where the response magnitude is the highest ( $\sim 6 \mathrm{~N}$, Fig. 2.c). The period value is about $\mathrm{T}_{\mathrm{B}}=0.92 \mathrm{~s}$. Expressed in length unit, it is equal to $d_{B} \approx 4.6 \mathrm{~mm}$ which corresponds to the unit cell (periodic geometry) length of the fabric (Fig. 1.b). This friction signal occurs when the two samples are perfectly superimposed (i.e. the higher zone of the bottom layer encounters the lower zone of the upper sample). In this configuration, the fabric/fabric contact behaviour consists in the superposition of two phenomena 
(Fig. 3): yarn/yarn sliding friction that occurs between the yarns oriented in the stroke direction and the shocks that take place between the transverse yarns of each sample, at each period of the unit cell, at the same time everywhere on the sample width. Shock's phenomenon takes place because the warp yarns overhang the weft yarns (Fig. 3). Reaction force due to this phenomenon increases leading to high maximum loads values (peaks of zone B). Once the obstacle, the fabric/fabric contact behaviour will be the sum of the sliding friction between the different yarns of the two samples (warp/warp, weft/weft and weft/warp) which tends to minimize the tangential loads.

The second period which is the duration separating two maximum load values when the response magnitude is the lowest ( $\sim \mathrm{N}$, Fig. 2.c) is associated to the zone A. Its value is about $\mathrm{T}_{\mathrm{A}}=0.46 \mathrm{~s}$. It corresponds to the distance between two consecutive yarns that is equal to the period $\mathrm{d}_{\mathrm{A}} \approx 2.3 \mathrm{~mm}$ (Fig. 1.b). This signal occurs when the samples are shifted by half of a geometrical period. In that configuration, the contact period is lower $\left(\mathrm{T}_{\mathrm{A}}=0.46 \mathrm{~s}\right)$ and is repeated every half geometrical period $\left(\mathrm{d}_{\mathrm{A}} \approx 2.3 \mathrm{~mm}\right)$. The shock between the yarns is also lower. As a consequence, lower maximum tangential loads values can be observed.

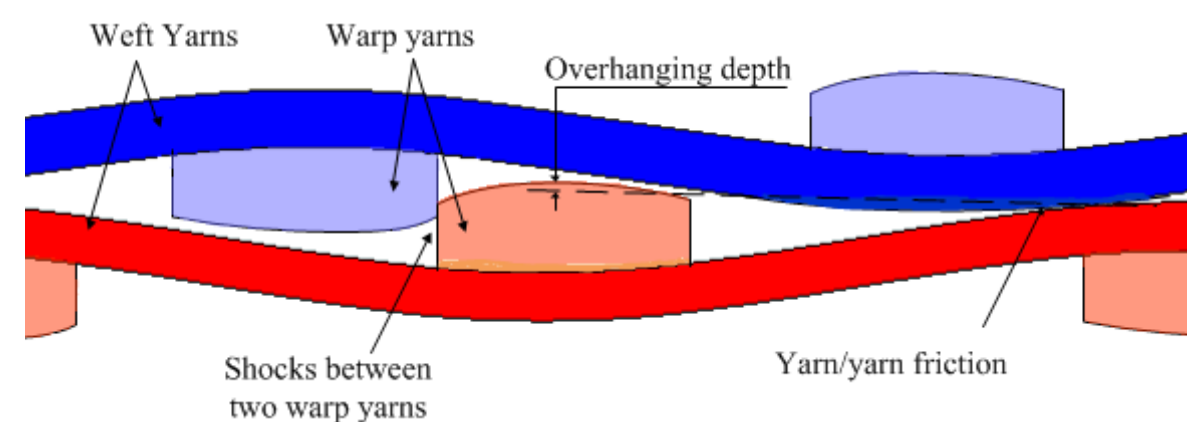

Figure 3 : phenomena occur during fabric/fabric contact behaviour for plan weave fabric

The transition zone (Fig. 2.c) consists of the progressive appearing and disappearing of an additional peak, and thus the coexistence of peaks with the two characteristic periods and amplitudes cited above. At this zone, the relative position between the two samples is between the two extreme shifts and thus the signal is a combination of these two configurations.

As a matter of conclusion, we can say that the characteristic period values found in the friction test signal are similar to the meso geometrical parameters of the fabric and the number of the observed zone is function of the relative positioning between the two samples. So, the observed behaviour correlates with the fabric meso-structure and the relative positioning between the pair of samples.

\section{Effect of the relative orientation of the two plies}

During forming thick parts, the plies can be stacked with various orientations in order to accommodate the required mechanical specifications of the application. However, these orientations will generate variations of friction behaviour between the different plies and therefore the tangential loads involved. These loads may lead to the generation of defects such as fabric unweaving. It is then crucial to study the evolution of the friction forces as a function of the ply angles in order to possibly optimize the configuration of the plies stacking to avoid defects.

Different ply/ply orientations have been tested for the plain weave fabric from $0^{\circ} / 0^{\circ}$ to $0^{\circ} / 90^{\circ}$. The position $0^{\circ} / 0^{\circ}$ is considered as the reference position where the weft yarns of the two samples are oriented in the stroke direction. For the other configurations, the upper sample is reoriented and the bottom sample remains in the same position $\left(0^{\circ}\right)$. Considering the phenomena involved during fabric/fabric contact behaviour and the weaving architecture, it's expected to have a symmetrical evolution of the friction coefficient with a minimum value at the orientation of $0^{\circ} / 45^{\circ}$. So, it have been decided to scan only orientations between $0^{\circ} / 0^{\circ}$ and $0^{\circ} / 45^{\circ}$ with an angles variation of $5^{\circ}$. For 
each configuration, at least ten tests were carried out with a $5 \mathrm{~mm} / \mathrm{s}$ displacement speed for the bottom sample and a normal load $\mathrm{N}=10 \mathrm{~N}$. The results of the average friction coefficient and the standard deviation as a function of the relative orientation are shown in figure 4.a.

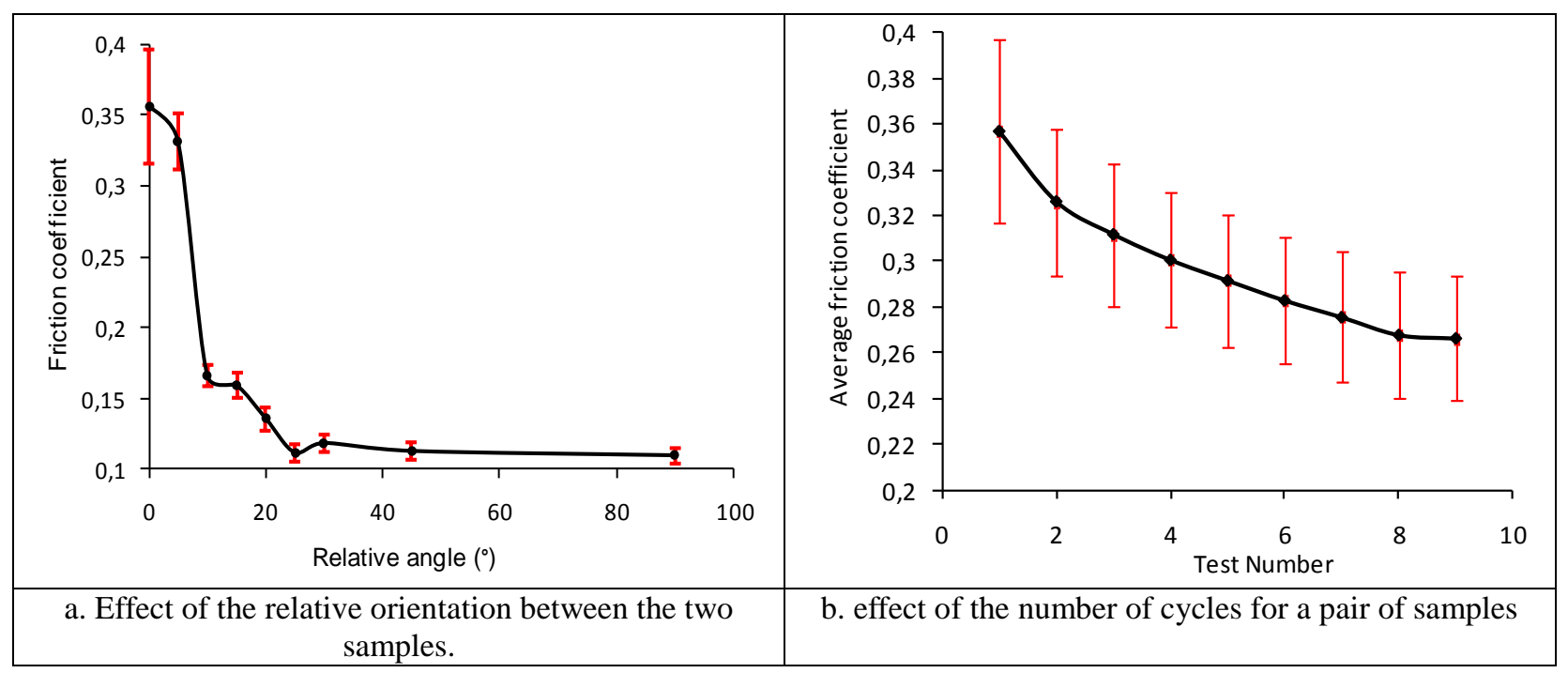

Figure 4: Average friction coefficient and average standard deviation as a function of the relative orientation and cycling. $\mathrm{v}=5 \mathrm{~mm} / \mathrm{s}, \mathrm{N}=10 \mathrm{~N}$.

When the angle between yarns increases, a significant decrease of the average coefficient and of the standard deviation is observed. When the yarns are not parallel, contacts between yarns do not appear at the same time everywhere on the sample width. As a consequence, a decrease of the friction load is expected. As expected, the minimum friction coefficient is observed for yarn angles of about $45^{\circ}$. However, at an angle of $25^{\circ}$, the friction coefficient values remain constant for higher ply/ply angles and an asymptotic value is reached (fig. 4.a). The achieved value is about one-third of the friction coefficient at the reference position $0^{\circ} / 0^{\circ}$. It is also interesting to notice that although the weft yarns are parallel to the warp yarns when the orientation $0 \% 190^{\circ}$ is considered, the friction coefficient is lower than for the $0^{\circ} / 0^{\circ}$ orientation. This result tends to confirm the impact of the weaving parameters. This plain weave fabric is therefore far from being balanced.

\section{Effect of cycling}

Cycling results were carried out on different pair of glass plain weave samples tested in the position $0^{\circ} / 0^{\circ}$ in the precedent section. The evolution of the friction coefficient is presented on figure 4.b. Grinding effect is observed which result in the decrease of the average friction load and standard deviation until reaching an asymptotic value (Fig. 4.b). This effect can be attributed to the abrasion of the material itself but also to fibre reorganisations under contact loads. This phenomenon is not surprising because it is classically encountered in dry reinforcement fabrics testing, whatever the type of solicitation applied (shear, biaxial, bending,...). Consequently, the number of cycles has to be taken into consideration when looking at the friction results. Two particular values are more interesting: the first cycle and the asymptotic ones. The first because it is the one that is mainly encountered in the multi-layer forming process and the asymptotic value because it makes it possible to perform many tests without replacing the samples.

\section{Conclusion}

The knowledge of the contact behaviour between layers of woven fabric is of particular importance when multi-ply forming is concerned. The results shown that fabric/fabric contact behaviour consists in the superposition of yarn/yarn sliding friction phenomenon and shocks phenomenon that take place between the overhanging transverse yarns of each sample. These shocks lead to a periodic signal where the period and the amplitude are linked to the fabric meso- 
structure, the relative positioning between the two samples and the fabric process parameters. A substantial variation of the tangential load, and thus the friction coefficient is occurred while all the test parameters remained constant. Consequently, using an average friction coefficient will lead to a high amount of uncertainties in the mechanical analysis of these materials.

In addition, the sample relative orientation has a significant influence on the friction response. The meso-architecture is responsible for the high variations of the friction coefficient as a function of the ply orientations for different fabrics. These preliminary experiments have also pointed out a honing (effect classically observed in dry fabric testing) through cyclic experiments. It has been attributed to fibres material abrasion and to fibre reorganisation in the yarn.

Variations of the friction load magnitude observed may lead to generates defects such as fabric unweaving or wrinkles. It then could be considered when trying to optimise multi-ply forming

\section{References}

[1] S. Hivet G., Allaoui S., Soulat D. Wendling A. Chatel, Analysis of woven reinforcement preforming using an experimental approach, The 17th International Conference on Composite Materials., EICC, Edinburgh, UK, 27-31 Jul 2009.

[2] K. Vanclooster, S. Lomov, and I. Verpoest, Simulation of multi-layered composites forming, International Journal of Material Forming. 3 (2010) 695-698.

[3] N. Hamila, P. Boisse, A meso macro three node finite element for draping of textile composite performs, Applied Composite Materials. 14 (2007) 235-250.

[4] J. Launay, G. Hivet, A.V. Duong, and P. Boisse, Experimental analysis of the influence of tensions on in plane shear behaviour of woven composite reinforcements, Composites Science and Technology. 68 (2) (2008) 506-515.

[5] J. Cao, R. Akkerman, P. Boisse, J. Chen, H.S. Cheng, E.F. de Graaf, J.L. Gorczyca, P. Harrison, G. Hivet, J. Launay, W. Lee, L. Liu, S.V. Lomov, A. Long, E. de Luycker, F. Morestin, J. Padvoiskis, X.Q. Peng, J. Sherwood, Tz. Stoilova, X.M. Tao, I. Verpoest, A. Willems, J. Wiggers, T.X. Yu, B. Zhu, Characterization of mechanical behavior of woven fabrics: Experimental methods and benchmark results, Composites Part A. 39 (6) (2008) 1037-1053.

[6] E. de Bilbao, G. Soulat, D. Launay, J. Hivet, A. Gasser, Experimental study of bending behaviour of reinforcements, Experimental Mechanics. 50 (3) (2010) 333-351.

[7] R. H. W. ten Thije, R. Akkerman, Design of an experimental setup to measure tool-ply and plyply friction in thermoplastic laminates, International Journal of Material Forming. 2 (2009) 197200.

[8] S. Rebouillat, Tribological properties of woven para-aramid fabrics and their constituent yarns, Journal of Materials Science. 33 (1998) 3293-3301.

[9] Jennifer L. Gorczyca, James A. Sherwood, Lu Liu, Julie Chen, Modeling of friction and shear in thermostamping of composites: part I, Journal of Composite Materials. 38 (21) (2004) 19111929.

[10]S. Allaoui, G. Hivet, A. Wendling, D. Soulat, S. Chatel, Experimental approach for optimizing dry fabric formability, The 14th European Conference on Composite Materials (ECCM 14), Budapest, Hungary, ID347-ECCM14, 7-10 June, 2010.

[11] G. Hivet, S. Allaoui, B.T. Cam, P. Ouagne, D. Soulat, Design and potentiality of an apparatus for measuring yarn/yarn and fabric/fabric friction, Experimental Mechanics. (2011), DOI: 10.1007/s11340-011-9566-0.

[12] S. Allaoui , G. Hivet, A. Wendling, P. Ouagne, Soulat, Influence of the dry woven fabrics meso-structure on fabric/fabric contact behaviour, Journal of Composite Materials, Accepted (2011). 